\title{
Using the 12-item short form health survey (SF-12) to assess self rated health of an engaged population impacted by hurricane Harvey, Houston, TX
}

\author{
Garett T. Sansom ${ }^{1 *}$, Katie Kirsch ${ }^{2}$ and Jennifer A. Horney ${ }^{3}$
}

\begin{abstract}
Background: In the last decade there has been an increase in community-based organizations providing support and educational outreach to populations effected by hazards. Prior research has demonstrated various roles that community social capital can play in both the enhancement of disaster preparedness and the mitigation of physical and mental health impacts following a natural disaster.

Methods: To assess self-reported health of residents of South Houston, Texas impacted by Hurricane Harvey, attendees of a community event completed a survey that included the 12 item short form health survey version 2 (SF-12v2).

Results: Although survey participants were older and more likely to be African-American than the overall population of Houston, they had higher mental health composite scores that the national average, with increases in mental wellbeing associated with a longer length of residence in their neighborhood.

Conclusions: The City of Houston, with highly segregated, socially vulnerable populations at high risk from natural hazards, should consider ways to support community engagement around disaster preparedness, response, and recovery that may build community cohesion and improve post-disaster mental health.
\end{abstract}

Keywords: Self-rated health, Disasters, Resilience, Social capital, Community engagement

\section{Background}

Research has consistently demonstrated that environmental justice communities are disproportionately impacted by proximate sources of pollution, toxic exposures, and other hazards that result in excess risks for human health outcomes based on race, income, housing segregation, and other factors [1-5]. However, individuals living in communities at risk may experience environmental issues in different ways. For example, in a previous study of predominantly Hispanic residents of an environmental justice community located adjacent to the Houston Ship Channel (HSC), respondents reported significantly lower selfreported physical health $(p<0.001)$, which was negatively correlated with the length of time a resident had been

\footnotetext{
* Correspondence: sansom@tamu.edu

${ }^{1}$ Research Assistant Professor, Environmental and Occupational Health, Texas A\&M University School of Public Health, College Station, TX 77840, USA Full list of author information is available at the end of the article
}

living in the neighborhood $(p<0.001)$ [6]. However, among this population, mental health scores did not differ from the national average nor change as a function of time living in the neighborhood. In a study of residents of Texas Gulf Coast counties conducted after Hurricane Harvey, residents exposed to Harvey had lower self-rated mental health than the U.S national population (mean mental composite score $(\mathrm{MCS})=34.58$, standard deviation $(\mathrm{SD})=8.89)$ [7]. Because the 12-item Short Form Health Survey version 2 (SF-12v2) is a widely validated measure of self-reported physical and mental health [8], and has been infrequently used to assess environmental or natural disaster related exposures, this study attempted to characterize the self-reported mental and physical health of members of a socially and physically vulnerable South Houston region who were highly engaged in a community non-profit whose focus was related to emergency preparedness and recovery following Hurricane Harvey. 
Specifically, identifying the potential mitigating effects of increased engagement on the mental health of communities that experience natural disasters.

Environmental justice communities are communities with low socioeconomic status (SES) and minority-majority populations that experience disproportionate exposure to negative environmental conditions compared to more affluent, majority white communities in the U.S. [9, 10]. Over the past 50 years, race has remained one of the most important factors in explaining residential segregation in the City of Houston [11]. Industrial development has primarily been concentrated in east and south Houston neighborhoods, while more affluent residents and the services and amenities associated with them, have primarily developed in the western and northern portions of Houston [12]. Among other factors, these patterns of development mean that African-American, Hispanic, and other minority residents of Houston became increasingly integrated with one another in east and south Houston [13].

A lack of zoning in Houston has furthered these types of land use and urban development inequities, while exposing residents to pollution from more freeway miles than any comparable region of the U.S. $[14,15]$. Vulnerable communities in the City of Houston are disproportionately exposed to polycyclic aromatic hydrocarbons (PAHs) associated with transportation infrastructure [16, 17], heavy metals in standing water [18], detectable lead levels in drinking water [19], and outdated and ineffective infrastructure to handle flooding events [20]. These conditions are being further exacerbated by simultaneous increases in the severity and frequency of inland precipitation [21], the combined effects of sea-level rise, subsidence, and storm surge [22], and increases in the proportion of impermeable surfaces as the result of population growth and development [23].

This increased flood risk in Houston was evident following Hurricane Harvey, which made landfall along the Texas Gulf Coast in August 2017 and became the wettest tropical cyclone to impact the U.S., inundating $70 \%$ of the City of Houston at a level of at least 18 in [24].. Using inundation maps produced by the Federal Emergency Management Agency (FEMA) and the Harris County Flood Control District (HCFCD) following Hurricane Harvey, Chakraborty, Collins, and Grineski (2019a) demonstrated that the greatest floodwater inundation levels were observed in areas with greater proportions of nonHispanic Black and economically disadvantaged residents [25]. The extent of flooding, as measured by FEMA's Hurricane Harvey Inundation Footprint aerial map, was statistically significantly higher in neighborhoods with a higher proportion of disabled residents, with the greatest risk observed among ambulatory- and cognitive-type disabilities [26]. Across Harris County, neighborhoods with a higher proportion of individuals with one or more disabilities, including neighborhoods with high rates of cognitive- and hearing-type disabilities, were more likely to be located nearer to facilities required by the U.S. Environmental Protection Agency (EPA) to submit Risk Management Plans due to their hazardous potential [26].

\section{Methods \\ Study setting}

In October 2017, research and engagement staff from the Texas A\&M University Institute for Sustainable Communities (IfSC) attended a Community Breakfast event hosted by Charity Productions, a Houston-based non-profit focused on emergency management and public safety issues. Charity Productions hosts quarterly breakfast meetings where community attendees can participate in educational outreach, civic engagement, and community strengthening activities. Often attended by more than 200 residents of Houston, the community breakfasts also include the distribution of fact-based information about hazards and disasters and the opportunity for attendees to participate in communityengaged research projects that focus on collecting data that can help increase community cohesion and resilience. During the October 2017 event, held approximately 2 months after Hurricane Harvey made landfall along the Texas Gulf Coast south of Houston, the agenda focused on how community agencies and residents could partner with academic institutions to better prepare for and recover from increasingly frequent and severe natural hazards like Hurricane Harvey. Attendees were those who had participated within Charity Productions events for several years and attended the quarterly meetings and periodic seminars. Following presentations by elected officials and academic researchers, attendees were asked to complete a survey created by IfSC. More than $90 \%$ (138 of 153) of those who attended the breakfast and completed the survey reported a residential address in south Houston (Fig. 1).

\section{Survey instrument}

The survey included three sections. In the first part of the survey, respondents provided demographic information (e.g., gender, race/ethnicity, and age), location of primary residence, and years of tenure in current neighborhood. A second section was included to gauge respondent's perceptions of environmental risk and included questions related to concerns about air pollution, flooding, proximity to industrial facilities, access to public transportation, and housing conditions. The final section of the survey included the SF-12v2, which was adapted from the medical outcomes study [27]. The SF$12 \mathrm{v} 2$ has been validated for use in predicting the mental and physical health of populations without targeting specific health outcomes and shown to be reliable in U.S. 


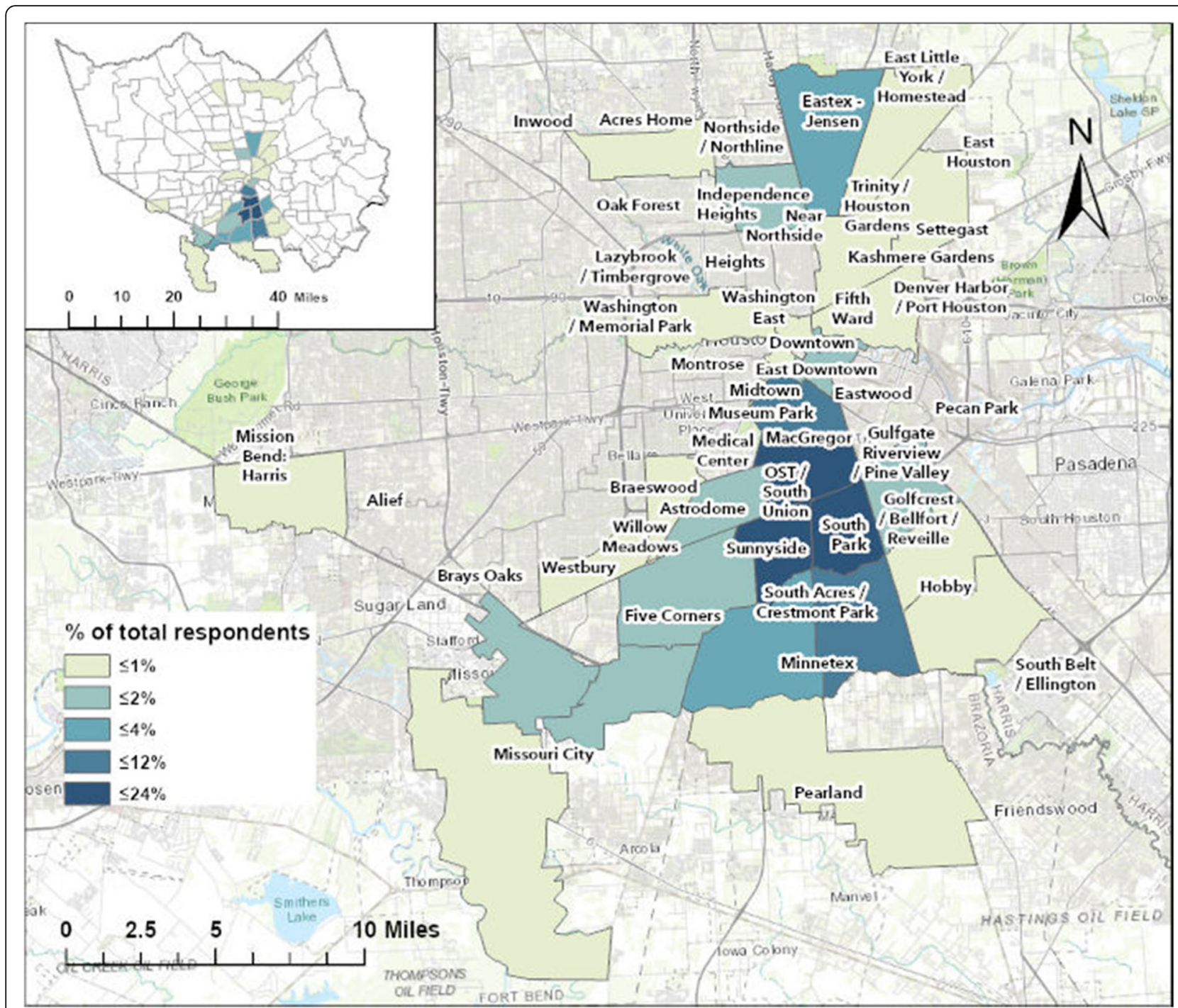

Fig. 1 Residential Address of Survey Participants by Houston Super Neighborhood; Percent of Respondents ( $N=153$ ). This figure depicts the neighborhoods in which participants primary homes are located. This figure was created by the authors utilizing ArcGIS by ESRI

and international populations $[28,29]$. The SF-12v2 has also been validated in several different languages [30, 31], within low SES populations [32], and among immigrant populations in the U.S. [33]. Using a norm-based algorithm it produces a composite score for selfreported mental and physical between 0 and 100, which allows for comparison between study populations and national averages [34].

\section{Data collection}

Eligible participants included members of Charity Productions and community breakfast attendees aged 18 years and older whose primary residence was in the Greater Houston, Texas area. Following the presentations by elected officials and academic researchers about post-Harvey recovery progress, attendees were given a brief overview of the purpose of the survey. Trained engagement staff and graduate students distributed the surveys, confirmed eligibility, and collected completed surveys. Response rates were calculated by summing the total number of eligible attendees, removing academic guests and invited speakers from outside the community, and dividing this number by those who returned a completed survey.

\section{Data analysis}

Responses to SF-12v2 questions were used to estimate a mental composite score (MCS) and physical composite score (PCS) for each subject on a 0 - and 100-point scale in accordance with the methods outlined by Ware et al. (2000) [34]. The national mean scores for both mental and physical health are standardized at 50; scores above 
this represent higher, or healthier, individuals than average. Overall and gender stratified mean MCS and PCS values for respondents were calculated and compared with the national mean using two-tailed t-tests. Multiple linear regression was used to assess the impact of time spent in the neighborhood, age, and gender on MCS and PCS. Coefficients of the covariates, along with their corresponding 95\% confidence intervals (95\% CI) were reported. Two-way scatterplots were created to visually examine associations between MCS and PCS and tenure of residence.

The City of Houston is organized into 88 Super Neighborhoods, which are geographically defined areas where residents, civic groups, and businesses work together to plan and set priorities that address shared concerns [35]. The primary residence of survey respondents were categorized into three groups: 1) South Houston Super Neighborhoods including Sunnyside, Southpark, South Acres/Crestmont Park, Central Southwest, and Greater Hobby Area; 2) Other Houston Super Neighborhoods including Midtown, Downtown, Eastex, and Greater Inwood; and 3) Areas outside the City of Houston, including Brenham, Humble, and League City. Statistical analyses were conducted using STATA 15 (College Station, TX) and Microsoft Excel (Redmond, Washington).

\section{Results}

One hundred fifty three surveys were completed at the October 2017 community breakfast (Response Rate = $81.4 \%)$. The majority of respondents were female $(83.7 \%$, $N=128)$, African-American (90.2\%, N=138), and 66 years of age or older $(79.1 \%, N=121)$, with the average age being 72 years $(S D=10.1$ years) (Table 1$)$. Ninety percent $(\mathrm{N}=138)$ of respondents reported living in a Super Neighborhood located in South Houston (Fig. 1), and the average length of residence was 34.3 years $(\mathrm{SD}=$ 20.2 years). Two in five $(39.1 \% ; N=61)$ participants reported that flooding was an issue in their neighborhood, and $35.9 \%(N=56)$ reported pollution was their largest concern. Fifteen percent $(N=24)$ identified public transportation as an unmet need and $10.3 \%(N=16)$ identified insufficient public services and city maintenance issues.

Respondents had higher MCS than the U.S. mean of 50, with MCS for women of 52.19 (95\% CI: 51.06, 53.32) and MCS for men of 53.22 (95\% CI: 50.87, 55.56). However, PCS for women was 41.59 (95\% CI: 40.74, 42.45) and PCS for men was 40.15 (95\% CI: 36.94, 43.47) significantly lower - nearly a full standard deviation - below national mean scores (Table 2). These findings remained consistent after adjusting for the age of respondents (There was no statistically significant correlation between PCS and years lived in the neighborhood (Fig. 2).
Table 1 Distribution of study respondents by gender, race/ ethnicity, age, and location of primary residence

\begin{tabular}{ll}
\hline Characteristic & $\mathrm{N}(\%)^{\mathbf{a}}$ \\
\hline $\begin{array}{l}\text { Gender } \\
\text { Male }\end{array}$ & $25(16.3 \%)$ \\
Female & $128(83.7 \%)$ \\
Race / Ethnicity & \\
$\quad$ Non-Hispanic White & $1(0.7 \%)$ \\
African American & $138(90.2 \%)$ \\
Refused & $14(9.2 \%)$ \\
Age in Years & \\
18-35 & $2(1.3 \%)$ \\
$36-65$ & $30(19.6 \%)$ \\
$66-80$ & $80(52.3 \%)$ \\
$80+$ & $27(17.6 \%)$ \\
Refused & $14(9.2 \%)$ \\
Location of Primary Residence & \\
South Houston, Texas Super Neighborhoods & $138(90.2 \%)$ \\
Other Houston, Texas Super Neighborhoods & $8(5.2 \%)$ \\
Areas outside of Houston, Texas city limits & $6(3.9 \%)$ \\
Refused & $1(0.7 \%)$ \\
\hline aalues may not equal 100\% due to rounding
\end{tabular}

avalues may not equal $100 \%$ due to rounding

However, longer length of residence in the neighborhood was positively correlated with MCS $\left(R^{2}=0.034\right.$; $\mathrm{p}=0.031$ ) (Fig. 3).

Although mean MCS and PCS among both male and female respondents were significantly different than the standardized national average, in multiple linear regression models, other than residence tenure and MCS scores, there were no differences in MCS or PCS by gender or age of respondents and PCS was not affected by tenure (Table 3).

\section{Discussion}

In this sample of Houston residents that attend communal events through Charity Productions and attended a community engagement event specifically focused on disaster preparedness and recovery from Hurricane

Table 2 Two-tailed $t$ tests of mean mental and physical composite scores by gender compared to the standardized national average of 50

\begin{tabular}{|c|c|c|c|c|}
\hline Group & $t$ value & Mean & $95 \% \mathrm{Cl}$ & $p$-value \\
\hline \multicolumn{5}{|c|}{ Mental Composite Score } \\
\hline Male & 2.83 & 53.22 & $50.87,55.56$ & 0.005 \\
\hline Female & 3.83 & 52.19 & $51.06,53.32$ & $<0.001$ \\
\hline \multicolumn{5}{|c|}{ Physical Composite Score } \\
\hline Male & -6.32 & 40.15 & $36.94,43.37$ & $<0.001$ \\
\hline Female & -19.53 & 41.59 & $40.74,42.45$ & $<0.001$ \\
\hline
\end{tabular}


$\mathrm{R}^{2}=0.011(\mathrm{p}$-value $=0.222)$

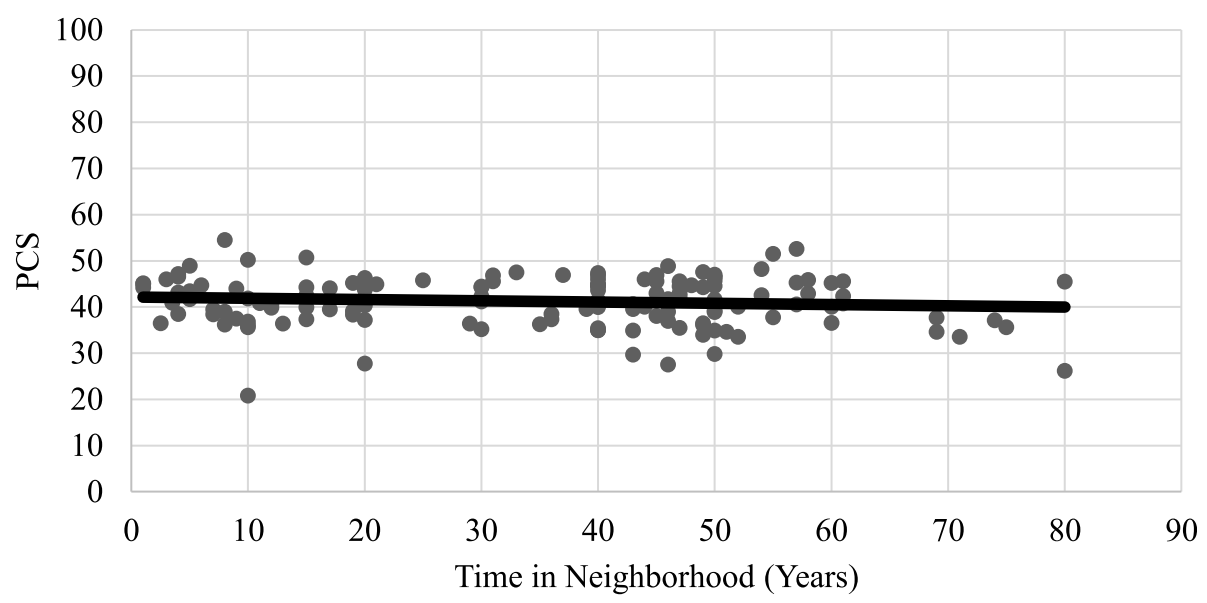

Fig. 2 Physical composite score (MCS) by years lived in the neighborhood

Harvey, $90 \%$ of respondents reported living in a majority minority South Houston Super Neighborhood, including Central Southwest, Sunnyside, Southpark, South Acres / Crestmont Park, and Greater Hobby Area. South Houston neighborhoods shoulder a burden of excess rates of poverty and unemployment [36] and are susceptible to flood-related damage and exposure opportunities [37]. These neighborhoods have been identified as highly socially vulnerable and having low capacity to prepare for and respond to the stress of hazardous events due in part to their low SES, the prevalence of households that include children, the elderly, or disabled members, a lack of access to transportation, low rates of home ownership, and minority race/ethnicity [38].

While mental and physical health are generally correlated, in this sample respondents reported better than average MCS and worse than average PCS. This is noteworthy as previous research with similar populations has found a rough parity between MCS and PCS. For instance, a cross-sectional study of low-income African American residents of Nashville, Tennessee $(N=1721)$ utilized the SF-12v2 to assess mental and physical health, finding that mental health and physical health often rose or fell together and mean MCS and PCS were only 6 points apart [39]. In this study, there was more than a 12-point difference in respondent's mean MCS and PCS, more than a standard deviation. These differences may offer insight into the benefits of promoting mental health among vulnerable communities through engagement in civic events focused on disaster preparedness, response, and recovery.

As this study was conducted among a group of community-engaged individuals attending one of several community events throughout the year, it is possible

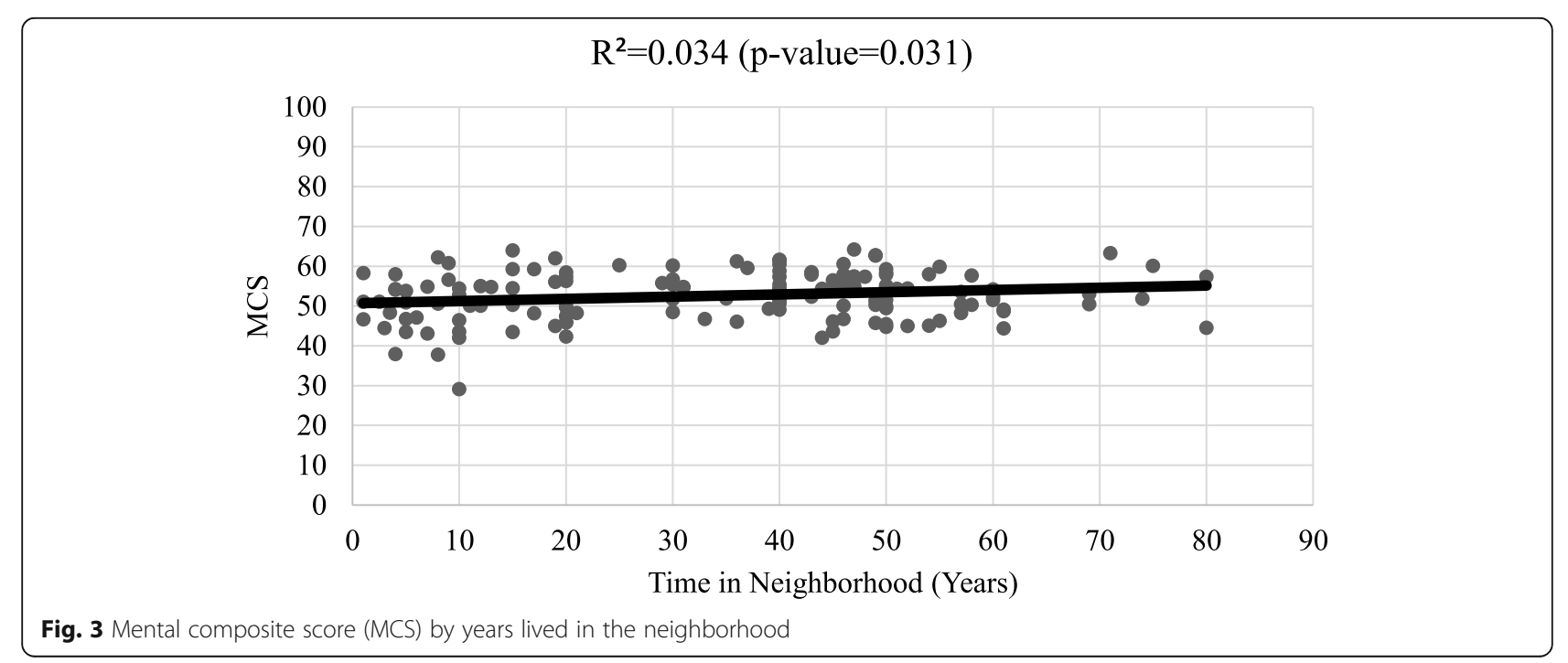


Table 3 Multiple linear regression comparing mental and physical composite scores by gender, tenure of current residence, and age

\begin{tabular}{lllll}
\hline Group & Coef & Std Err. & $95 \% \mathrm{Cl}$ & $p$-value \\
\hline Mental Composite Score & & & & \\
$\quad$ Gender (Female) & -1.24 & 1.46 & $-4.13,1.66$ & 0.394 \\
Tenure of Residence & 0.06 & 0.03 & $0.01,0.12$ & 0.031 \\
$\quad$ Age & 0.07 & 0.06 & $-0.53,0.19$ & 0.282 \\
Physical Composite Score & & & & \\
$\quad$ Gender (Female) & 0.48 & 1.28 & $-2.06,3.03$ & 0.711 \\
Tenure of Residence & -0.03 & 0.03 & $-0.08,-0.02$ & 0.211 \\
Age & 0.01 & 0.05 & $-0.09,0.12$ & 0.863 \\
\hline
\end{tabular}

that their engagement was beneficial to their mental health resilience to the impacts of Hurricane Harvey. In research after Hurricane Sandy, Lowe et al. (2015) identified socioeconomic disadvantage, non-Hispanic Black race, and older age as characteristics associated with higher rates of posttraumatic stress [40]. After Hurricane Katrina, white women, older women, and women with a partner were found to be more resilient from depression and post-traumatic stress disorder [41]. However, several models emerged after the Hurricane and the Deep Water Horizon oil spill that demonstrated ways in which faith-based, governmental, and academic groups could come together to improve disaster mental health and resilience $[42,43]$. These resident's long-term tenure in their neighborhoods may have facilitated community connections - of which attendance at this community event was one manifestation - that were protective and supported resilience that was operationalized through a relatively rapid return to a pre-disaster state [44]. Further, increased social cohesion, even outside experiencing hazardous events, has been demonstrated to mitigate many potentially negative impacts on mental health and could account for the relatively high MCS scores [45].

Also, among this sample, physical health remained consistent over increasing community tenure, whereas mental health showed a marked and significant improvement the longer individuals lived within their respective communities. Ample evidence exists indicating physical health issues within this community, for instance the mean life expectancy for Harris County and Houston, Texas in 2014 was approximately 79 years, while Sunnyside residents had an estimated mean life expectancy of only 71 years from 2010 to 2015 [46]. Although our sample was small, this lends support to the hypothesis that community cohesion can improve mental health, even in an aging community with physical health issues and provides initial evidence for a pathway to improve lives through interventions targeting communal networking improvement projects.
This study has several important limitations. Primarily this study lacks a matched comparison group to directly assess our results with other groups of differing SES, community cohesion, and exposure to the hurricane. Secondly, since the survey respondents were all attendees at a community engagement event, these findings may not be generalizable to residents of the same Super Neighborhoods that are not engaged in similar organizations. Further, as this event required individuals to travel to a designated location, it may have missed the most vulnerable and those with the greatest physical or mental health challenges. Although no mental and physical health assessments involving this population were conducted before Hurricane Harvey, the present study can provide baseline measures with which to compare future research and generate improved hypotheses. A strength of this study is that the survey was selfadministered, limiting potential response bias compared to an interviewer administered survey [47].

\section{Conclusion}

Improving our understanding of the complex relationship between the mental and physical health impacts of disasters and the potential for active engagement to mitigate these impacts through increasing individual resilience, even among minority residents of environmental justice communities, will require additional longitudinal research. In the meantime, these data can serve as a baseline for understanding the potential benefits of engagement on mental wellbeing after natural disasters within vulnerable communities.

\section{Abbreviations \\ EPA: U.S. environmental protection agency; FEMA: Federal emergency management agency; HCFCD: Harris county flood control district; \\ HSC: Houston ship channel; IfSC: The Texas A\&M university institute for sustainable communities; MCS: Mental composite score; PAH: Polycyclic aromatic hydrocarbons; PCS: Physical composite score; SES: Low \\ socioeconomic status; SF-12v2: 12 item short form health survey version 2}

\section{Acknowledgements}

Not applicable.

\section{Consent of publication}

Not applicable.

\section{Authors' contribution}

GS and JH collected survey data. GS analyzed and present statistical results. $\mathrm{GS}, J \mathrm{H}$, and KK were major contributors in writing the manuscript. All authors read and approved the final manuscript.

\section{Funding}

Research reported in this publication was supported by the National Institute of Environmental Health Sciences of the National Institutes of Health under Award Number P42ES027704, the Superfund Research Program (https://superfund. tamu.edu/). The funders had no role in study design, data collection and analysis, decision to publish, or preparation of the manuscript.

Availability of data and materials

The datasets used and/or analyzed during the current study are available from the corresponding author on reasonable request. 


\section{Ethics approval and consent to participate}

Participants were given an information sheet on details about the research and verbal consent was collected from each participant. Verbal consent was sought to decrease the time burden on participants and increase response rates. This research and approach was reviewed and approved by the Texas A\&M University Institutional Review Board (\#15-0648D).

\section{Competing interests}

The authors declare that they have no conflict of interest.

\section{Author details}

'Research Assistant Professor, Environmental and Occupational Health, Texas A\&M University School of Public Health, College Station, TX 77840, USA. ${ }^{2}$ Research Associate, Epidemiology and Biostatistics, Texas A\&M University School of Public Health, College Station, TX 77840, USA. ${ }^{3}$ Professor and Founding Director, Epidemiology Program, University of Delaware, Newark, DE 19713, USA.

\section{Received: 18 November 2019 Accepted: 13 February 2020 \\ Published online: 19 February 2020}

\section{References}

1. Bullard RD, Wright BH. Environmental justice for all: community perspectives on health and research. Toxicol Ind Health. 1993;9(5):821-41.

2. Perlin $S$, Sexton $K$, Wong D. An examination of race and poverty for populations living near industrial sources of air pollution. J Expo Anal Environ Epidemiol. 1999;9:29-48.

3. Brulle R, Pellow D. Environ Justice: Hum Health Environ Inequalities Annu Rev Public Health. 2006;27(1):103-24.

4. Norton JM, Wing S, Lipscomb HJ, Kaufman JS, Marshall SW, Cravey AJ. Race, wealth, and solid waste facilities in North Carolina. Environ Health Perspect. 2007;115(9):1344-50

5. Wilson SM. Environmental justice movement: a review of history, research, and public health issues. J Public Manage Soc Policy. 2010;16(1):19-50.

6. Sansom G, Parras J, Parras A, Nieto Y, Arellano Y, Berke P, McDonald T, Shipp E, Horney JA. The impacts of exposure to environmental risk on physical and mental health in a small geographic community in Houston, TX. Community Health. 2017:42(4):813-8.

7. Karaye IM, Ross AD, Perez-Patron M, Thompson C, Taylor N, Horney JA. Factors associated with self-reported mental health of residents exposed to hurricane Harvey. Prog Disaster Sci. 2019;2:100016.

8. Ware JE Jr, Kosinski M, Keller SD. A 12-Item Short-Form Health Survey: construction of scales and preliminary tests of reliability and validity. Med Care. 1996:34(3):220-33.

9. Bullard R. Dumping in Dixie: race, class, and environmental quality. 3rd ed. Boulder: Westview Press; 2000.

10. Morello-Frosch, R. Pastor, M. Porras, C. Sadd, J. Environmental justice and regional inequality in southern California: implications for future research. Environmental Health Perspectives 1 April 2002 https://doi.org/https://doi. org/10.1289/ehp.02110s2149

11. Sui DZ, Wu XB. Changing patterns of residential segregation in a prismatic metropolis: a lacunarity-based study in Houston, 1980-2000. Environ Plann B: Plann Des. 2006;33(4):559-79.

12. Mieszkowski P, Smith B. Analyzing urban decentralization: the case of Houston. Reg Sci Urban Econ. 1991;21(2):183-99.

13. Strait JB, Gong G. Ethnic diversity in Houston, Texas: the evolution of residential segregation in the Bayou City, 1990-2000. Popul Rev. 2010;49(1): 60-4.

14. Texas Transportation Institute (TTI) (2003). Urban Mobility Study. Retrieved from: http://mobility.tamu.edu.srv-proxy2.library.tamu.edu/ums/report. Accessed 1 Nov 2019

15. Qian Z. Without zoning: urban development and land use controls in Houston. Cities. 2010;27(1):31-41.

16. Yelena Y. Naumova, Steven J. Eisenreich, Barbara J. Turpin, Clifford P. Weisel, Maria T. Morandi, Steven D. Colome, Lisa A. Totten, Thomas H. Stock, Arthur M. Winer, Shahnaz Alimokhtari, Jaymin Kwon, Derek Shendell, Jennifer Jones, Silvia Maberti, and Steven J. Wall Environmental Science \& Technology 200236 (12), 2552-2559 DOl: https://doi.org/10.1021/ es015727h.

17. Horney JA, Casillas GA, Baker E, Stone KW, Kirsch KR, et al. (2018) Comparing residential contamination in a Houston environmental justice neighborhood before and after hurricane Harvey. PLoS One 13(2): e0192660. https://doi. org/https://doi.org/10.1371/journal.pone.0192660.

18. Sansom G, Berke P, McDonald T, Shipp E, Horney J. Confirming the environmental concerns of community members utilizing participatorybased research in the Houston neighborhood of Manchester. Int J Environ Res Public Health. 2016:13:839.

19. Sansom, G. Cizmas, L. Aarvig, K. Dixon, B. Kirsch, K. Katare, A. Sansom, L. "Vulnerable populations exposed to Lead-contaminated drinking water" Int J Environ Res Public Health 2019, 16(15), 2745; https://doi.org/https://doi. org/10.3390/ijerph16152745.

20. Newman, G. Kim, JH, Berke, P, Merrill, J, Wang, Y. and Li, Q. From idle grounds to ecological infrastructure: the resilient Design of Manchester Neighborhood in Houston. Landscape Architecture Front 20164 (5): 68-84.

21. Zhu L, Quiring SM. Variations in tropical cyclone precipitation in Texas (1950 to 2009). J Geophysical Res: Atmospheres. 2013:118(8):3085-96.

22. Atkinson J, Smith J, Bender C. Sea-level rise effects on storm surge and nearshore waves on the Texas coast. J Waterw Port Coast Ocean Eng. 2013; 139(2):98-117

23. Brody $S$, Blessing $R$, Sebastian A, Bedient P. Examining the impact of land use/land cover characteristics on flood losses. J Environ Plan Manag. 2014; 57(8):1252-65.

24. Liberto D, Tom. Reviewing hurricane Harvey's catastrophic rain and flooding | National Oceanic and Atmospheric Administration. NOAA September. 2017;18:2017. https://www.climate.gov/news-features/event-tracker/ reviewing-hurricane-harveys-catastrophic-rain-and-flooding. Accessed 18 Sept 2018.

25. Chakraborty J, Collins TW, Grineski SE. Exploring the environmental justice implications of hurricane Harvey flooding in greater Houston, Texas. Am J Public Health. 2019;109(2):244-50.

26. Chakraborty J. Proximity to extremely hazardous substances for people with disabilities: a case study in Houston, Texas. Disabil Health J. 2019; 12(1):121-5.

27. Tarlov AR, Ware JE, Greenfield S, Nelson EC, Perrin E, Zubkoff M. The medical outcomes study: an application of methods for monitoring the results of medical care. JAMA. 1989;262(7):925-30. https://doi.org/10.1001/jama.1989. 03430070073033.

28. Gandek, B. Ware, J. Aaronson, N. Apolone, G. Bjorner, J. Brazier, J. Bullinger, M. Kaasa, S. Leplege, A. Prieto, L. Sullivan, M. (1998) Cross-validation of item selection and scoring for the SF-12 health survey in nine countries: results from the IQOLA project, J Clin Epidemiol, Volume 51, Issue 11, https://doi. org/10.1016/S0895-4356(98)00109-7.

29. Lim, L.LY. \& Fisher, J.D. (1999) Use of the 12-item short-form (SF-12) health survey in an Australian heart and stroke population Qual life res 8: 1. https:// doi.org/https://doi.org/10.1023/A:1026409226544.

30. Hoffmann, C. McFarland, B. . Kinzie, d. Bresler, I. Rakhlin, d. Wolf, s. Kovas, a. (2005) Psychometric properties of a Russian version of the SF-12 health survey in a refugee population. Compr Psychiatry Volume 46, Issue 5, Pages 390-397.

31. Nübling, M., Andersen, H. H., \& Mühlbacher, A. (2006). Entwicklung eines Verfahrens zur Berechnung der körperlichen und psychischen Summenskalen auf Basis der SOEP-Version des SF 12 (Algorithmus) (No. 16). DIW Data Documentation.

32. Larson CO. Use of the SF-12 instrument for measuring the health of homeless persons. Health Serv Res. 2002:37(3):733-50.

33. Franzini L, Fernandez-Esquer ME. Socioeconomic, cultural, and personal influences on health outcomes in low income Mexican-origin individuals in Texas. Soc Sci Med. 2004;59(8):1629-46.

34. Ware JE, Kosinski M, Dewey JE. How to score version 2 of the SF-12 health survey (standard \& acute forms). QualityMetric Incorporated: Lincoln; 2000.

35. City of Houston (2019). Super Neighborhoods. Retrieved from: http://www. houstontx.gov/superneighborhoods/. Accessed 8 July 2017.

36. Douglas E, Rubio J. Houston region's poverty rate increases in 2018 as household income flattens. In: Business - Houston chronicle; 2019. Retrieved from: https://www.houstonchronicle.com/business/article/Houston-region-spoverty-rate-increases-in-2018-14468509.php. Accessed 23 Nov 2019.

37. City of Houston. (2016). Draft Houston action plan for disaster recovery 2015 flood events. Retrieved from: http://houstontx.gov/housing/2015-DraftAction-Plan-for-Disaster-Recovery.pdf. Accessed 13 Nov 2019.

38. Centers for Disease Control and Prevention (CDC) (2019). CDC's Soocial Vulnerability Index Harris County, TX. Retrieved from: https://svi.cdc.gov/ Documents/CountyMaps/2016/Texas/Texas2016_Harris.pdf. Accessed 10 Aug 2019. 
39. Larson CO, Schlundt D, Patel K, Hargreaves M, Beard K. Validity of the SF-12 for use in a low-income African American community-based research initiative (REACH 2010). Prev Chronic Dis. 2008;5(2).

40. Lowe SR, Sampson L, Gruebner O, Galea S. Psychological resilience after hurricane Sandy: the influence of individual-and community-level factors on mental health after a large-scale natural disaster. PloS One. 2015;10(5): e0125761.

41. Harville EW, Xiong X, Buekens P, Pridjian G, Elkind-Hirsch K. Resilience after hurricane Katrina among pregnant and postpartum women. Womens Health Issues. 2010;20(1):20-7.

42. Aten JD, Topping S, Denney RM, Bayne TG. Collaborating with African American churches to overcome minority disaster mental health disparities: what mental health professionals can learn from hurricane Katrina. Prof Psychol: Res Pract. 2010;41(2):167.

43. McCabe OL, Semon NL, Lating JM, Everly GS Jr, Perry CJ, Moore SS, Mosley AM, Thompson CB, Links JM. An academic-government-faith partnership to build disaster mental health preparedness and community resilience. Public Health Rep. 2014;129(6_suppl4):96-106.

44. Zahran S, Peek L, Snodgrass JG, Weiler S, Hempel L. Economics of disaster risk, social vulnerability, and mental health resilience. Risk Analysis: An International Journal. 2011;31(7):1107-19.

45. Fone D, Dunstan F, Lloyd K, Williams G, Watkins J, Palmer S. Does social cohesion modify the association between area income deprivation and mental health? A multilevel analysis. Int J Epidemiol. 2007;36(2):338-45.

46. Houston Health Department. (2019). Health disparity and health inequity. 2019 Trends and data report. Houston/Harris County. Section 2: Morbidity and mortality. Retrieved from https://www.houstontx.gov/health/chs/ documents/Health-Disparities-Data-Report-II-2019-Morbidity-and-Mortality. pdf. Accessed 3 Nov 2019.

47. Eschbach K, Ostir G, Patel K, Markides K, Goodwin J. Neighborhood context and mortality among older Mexican Americans: is there a barrio advantage? Am J Public Health. 2004;94(10):1807-12.

\section{Publisher's Note}

Springer Nature remains neutral with regard to jurisdictional claims in published maps and institutional affiliations.

Ready to submit your research? Choose BMC and benefit from:

- fast, convenient online submission

- thorough peer review by experienced researchers in your field

- rapid publication on acceptance

- support for research data, including large and complex data types

- gold Open Access which fosters wider collaboration and increased citations

- maximum visibility for your research: over $100 \mathrm{M}$ website views per year

At $\mathrm{BMC}$, research is always in progress.

Learn more biomedcentral.com/submissions 